Claremont Colleges

Scholarship@ Claremont

WM Keck Science Faculty Papers

W.M. Keck Science Department

$1-1-1991$

\title{
The Species-Genus Relationship in Antillean Bat Communities
}

Donald A. McFarlane

Claremont McKenna College; Pitzer College; Scripps College

\section{Recommended Citation}

McFarlane, D.A. (1991). "The species-genus relationship in Antillean bat communities." Mammalia 55(3): 363-370.

This Article is brought to you for free and open access by the W.M. Keck Science Department at Scholarship @ Claremont. It has been accepted for inclusion in WM Keck Science Faculty Papers by an authorized administrator of Scholarship @ Claremont. For more information, please contact scholarship@cuc.claremont.edu. 


\title{
The species-genus relationship in Antillean bat communities
}

\author{
by D.A. MCFARLANE \\ Section of Mammalogy, Natural History Museum of Los Angeles County, \\ 900 Exposition Boulevard, Los Angeles, CA 90007
}

Summary. - The ratio of the number of species to the number of genera in an island community has long been recognised as a potential proxy indicator of competitive interaction. An analysis of this relationship in the bat fauna of the Antillean archipelago demonstrates that the observed species-genus ratios are significantly depressed below nullmodel expectations, and that the magnitude of this depression is inversely proportional to the $\log$ of the appropriate island area. These observations are consistent with the hypothesis that interspecific competition may play an important role in structuring Antillean bat communities.

Résumé. - La proportion du nombre d'espèces par rapport au nombre des genres dans une communauté insulaire a été reconnue comme un indicateur d'interactions compétitives. Une analyse de cette relation dans la faune des chauves-souris de l'archipel des Antilles montre que les proportions d'espèces/genres que l'on observe sont réduites de manière significative par rapport à l'hypothèse du modèle et que l'importance de cette réduction est inversement proportionnelle au log. de la surface de l'île. Ces observations concordent avec l'hypothèse que la compétition interspécifiques peut jouer un rôle important dans la structuration des communautés de chauves-souris antillaises.

\section{INTRODUCTION}

Several authors (Elton 1946 ; Grant 1966) have noted the apparent decrease in the average number of species per genus in island communities when compared with their mainland equivalents. According to Darwin (1878:59) : " As species of the same genus have usually, though by no means invariably, some similarity in habits and constitution, and always in structure, the struggle will generally be more severe between species of the same genus, when they come into competition with each other, than between species of distinct genera ". If this is the case, then as Harvey et al. (1983) have noted, competitive exclusion might be expected to distance congeneric taxa so that local communities should exhibit

Mammalia, t. 55, $n^{\circ}$ 3, 1991. 
species-genus ratios lower than those observed in the regional fauna as a whole. Furthermore, this effect should be strongest on small islands where extinction rates are high and the 'distancing' of congeneric taxa in niche space implies the extinction of one or more species.

The validity of this phenomenon has been questioned by Simberloff (1970) who noted that a decrease in the species-genus ratio must accompany a decrease in the number of species in the sample. In the most extreme case of an island with only a single species, the species-genus ratio must equal unity. The examination of 22 data sets, including assemblages of vertebrates, invertebrates, and plants, led Simberloff to conclude that in most instances the reported decrease in the species-genus ratio did not significantly exceed that predicted by null models generated from Monte-Carlo simulations. Simberloff also reported several instances of species-genus ratios in impoverished communities being higher than those predicted by the null models.

In this analysis I have tested the hypothesis that the observed species-genus ratios for Antillean island bat communities are lower than the ratios predicted by a null model generated by Monte-Carlo drawings from a regional species pool. I have also tested the hypothesis that the magnitude of the depression of the species-genus ratios is correlated with the size of the islands.

\section{METHODS}

A presence-absence data matrix of 56 species of bats extant on 25 Antillean islands was used to provide the regional species pool for the null model (Appendix 1). This species pool includes all taxa known to occur in the Antillean archipelago, sensu Baker and Genoways (1978), drawn from the literature through 1988. The 25 islands include all major and many minor members of the archipelago, with sizes ranging over 5 orders of magnitude.

Null-model species assemblages of sizes equal to each observed assemblage size were generated by randomized drawing without replacement from the species pool. For each observed species-assemblage size, 1000 Monte-Carlo simulations were performed and the mean and standard deviation of the mean number of genera were tallied. The probability of obtaining a value equal to or greater than the observed number of genera was determined directly by tallying the number of occurences in the simulation distribution $(\mathrm{N}=1000)$.

\section{RESULTS}

The 25 islands included in this analysis support 14 different species-assemblage sizes. Islands supporting assemblages of equal size also support assemblages with identical species compositions, with two exceptions. The two islands supporting 12 bat species each, Grenada and Dominica, host 10 and 12 genera respectively. The two islands supporting 9 species each, St. Vincent and Montserrat, host 8 and 9 genera respectively. Table 1 summarizes the observed assemblage sizes, 
the number of observed genera in these assemblages, the mean and standard deviation of the predicted number of genera derived from 1000 Monte-Carlo simulations, and the probability of equalling or exceeding the observed number of genera by chance alone.

In all instances, the observed number of genera exceeds the number of genera predicted by the null model (Fig. 1). A Wilcoxon Signed Rank test (Sokal and Rohlf 1981) of the differences between observed and predicted counts of genera demonstrates that the probability of obtaining this pattern by chance alone is very small $\left(\mathrm{n}=25, \mathrm{~T}_{\mathrm{s}}=0, \mathrm{P}<<0.005\right)$. Similarly, a Paired t-test (Sokal and Rohlf, 1981) demonstrates that the observed and predicted numbers of genera are significantly different $(t=7.81, \mathrm{df}=24, \mathrm{P}<<0.0005)$.

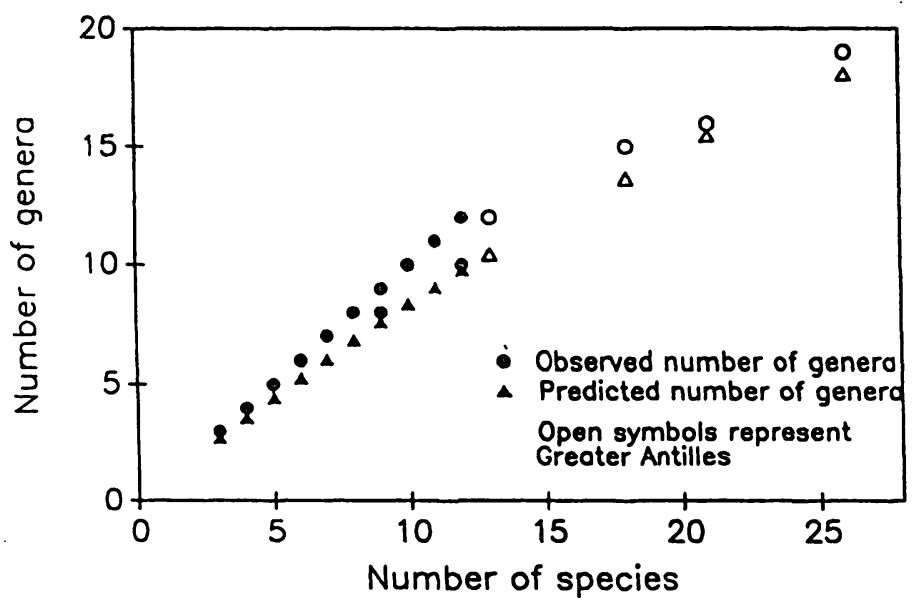

Fig. 1. - Relationship between observed and expected numbers of bat genera on Antillean islands of differing species-richness.

For assemblage sizes with only a single observed occurrence, the probabilities of obtaining the observed number of genera by chance do not fall below the 0.05 significance level. For assemblage sizes with multiple observed occurrences in the archipelago, overall probabilities range from 0.055 to 0.068 . Furthermore, Fisher's multiple probability test (Sokal and Rohlf 1981) demonstrates that the archipelago-wide observed pattern departs significantly from the null model (Fisher's statistic $=52.72, \mathrm{df}=32, \mathrm{P}<<0.025$ ). Figure 2 illustrates the relationship between the species-genus ratio and the log of island area for the 25 islands. A simple linear regression analysis of this relationship demonstrates a significant slope $(t=5.10, P<0.0005)$ and dependence of the ratio on island size $(F=25.99$, $\left.\mathrm{P}<0.0005, \mathrm{r}^{2}=0.531\right)$. However, the relationship is clearly curvilinear and is better fit by a third-order polynomial regression $\left(r^{2}=0.738\right)$. The relationship between the observed number of genera on an island and the species assemblage size on that island is even stronger (linear regression statistics ; $a=1.64, b=0.727$, $\mathrm{r}^{2}=0.968, \mathrm{~F}=686.69, \mathrm{p}<<0.0005$ ). However Figure 1 illustrates that the size of the deviation between observed and expected numbers of genera increases with assemblage size in the Lesser Antilles, but declines in the Greater Antilles. 
TABLEAU 1. - Summary statistics of the Monte-Carlo simulations. $\mathrm{S}=$ species richness (assemblage size). $O=$ observed number of genera. $M=$ mean expected number of genera based on 1000 Monte-Carlo simulations. SD $=$ standard deviation of the mean expected number of genera. $\mathbf{P}=$ probability of equalling or exceeding the observed number of genera by chance. Island area data from Lack (1976) and Lazell and Jarecki (1985).

\begin{tabular}{|c|c|c|c|c|c|c|}
\hline Islana & $(K m 2)$ & $\mathbf{s}$ & o & $M$ & SD & $\mathbf{P}$ \\
\hline Cuba &, 000 & 26 & 19 & 18.08 & 1.587 & 0.398 \\
\hline Jamaica & 1,400 & 21 & 16 & 25.47 & 1.478 & 0.488 \\
\hline Hispan101a 80 & 0.000 & 18 & 15 & 13.66 & 1.414 & 0.277 \\
\hline Puerto R1co & 9000 & 13 & 22 & 20.42 & 1.170 & 0.175 \\
\hline Dominica & 800 & 12 & 12 & 9.787 & 1.120 & 0.052 \\
\hline Grenada & 310 & 12 & 10 & 9.787 & 1.120 & 0.630 \\
\hline Guadeloupe & 1500 & 11 & 11 & 9.062 & 1.078 & 0.076 \\
\hline Martinique & 1100 & 10 & 10 & 8.337 & 1.009 & 0.113 \\
\hline Montserrat & 100 & 9 & 9 & 7.590 & 0.969 & 0.176 \\
\hline st. Vincent & 350 & 9 & 8 & 7.590 & 0.969 & 0.565 \\
\hline Gr. Cayman & 180 & 8 & 8 & 6.823 & 0.887 & 0.235 \\
\hline st. Lucia & 600 & 8 & 8 & 6.823 & 0.887 & 0.235 \\
\hline Antigua & 280 & 7 & 7 & 6.050 & 0.847 & 0.329 \\
\hline Barbados & 430 & 6 & 6 & 5.259 & 0.742 & 0.417 \\
\hline Barbuda & 160 & 6 & 6 & 5.259 & 0.742 & 0.417 \\
\hline St. John & 49 & 6 & 6 & 5.259 & 0.742 & 0.417 \\
\hline St. Martin & 85 & 5 & 5 & 4.439 & 0.632 & 0.511 \\
\hline Anguilla & 90 & 5 & 5 & 4.439 & 0.632 & 0.511 \\
\hline st. Eustatius & 21 & 5 & 5 & 4.439 & 0.632 & 0.511 \\
\hline St. Thomas & 70 & 5 & 5 & 4.439 & 0.632 & 0.511 \\
\hline st. Kitts & 180 & 4 & 4 & 3.584 & 0.568 & 0.623 \\
\hline st. Croix & 210 & 4 & 4 & 3.584 & 0.568 & 0.623 \\
\hline Guana & 3 & 3 & 3 & 2.710 & 0.495 & 0.730 \\
\hline Tortola & 54 & 3 & 3 & 2.710 & 0.495 & 0.730 \\
\hline Saba & 12 & 3 & 3 & 2.710 & 0.495 & 0.730 \\
\hline
\end{tabular}




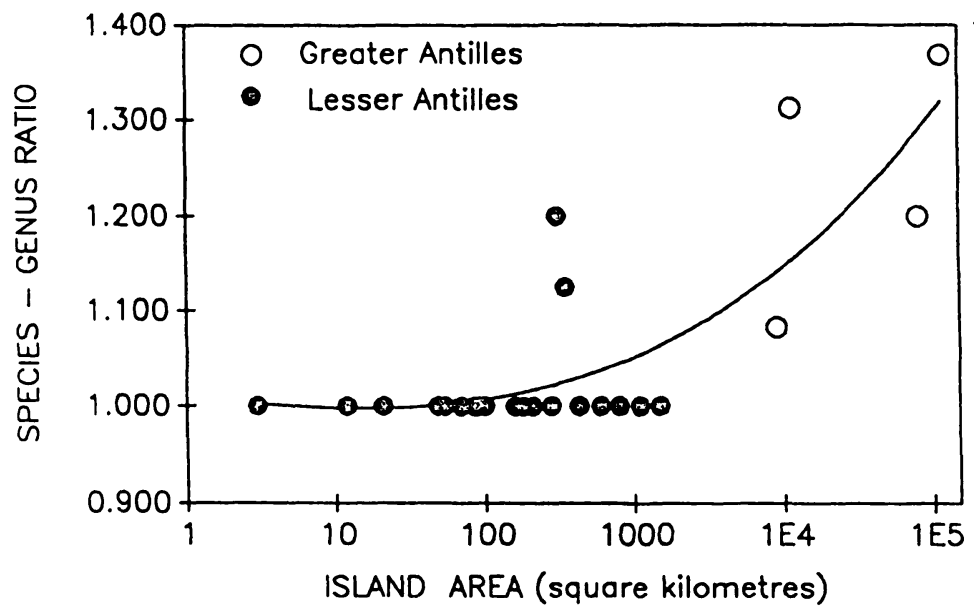

Fig. 2. - Relationship between the species-genus ratio and island area for the bat faunas of 25 Antillean islands.

\section{DISCUSSION}

The archipelago-wide pattern of bat species-genus relationships in the Antilles is consistently and significantly depressed below null-model expectations. Although individual island assemblages do not deviate from the null model at the $95 \%$ significance level, this is to be expected with sample sizes of one. Hopf and Brown (1986) have addressed this general problem and emphasized the necessarity of examining multiple assemblages of differing species richnesses. The Fisher multiple probability test, the Wilcoxon Signed Rank test, and the Paired t-test (Sokal and Rohlf 1981) leave no doubt that the Antillean archipelago exhibits a highly non-random pattern of species-genus relationships.

Drawing biological conclusions from deviations in null models requires some confidence in the appropriateness of the regional species pool from which the null model is constructed. If the species pool is an amalgam of two or more discontiguous groups of species, null model species-genus ratios will be depressed. This would have the effect of reducing the probability of obtaining a significant difference between the observed and null model patterns (a Type II error ; Zar, 1984), which has not been a problem in this study.

It is also worthwhile to address potential differences between species assemblages, which are simply lists of bats occurring on an island, and communities which are assemblages of species spatially and temporally coexisting on an island. On small islands these terms will usually be synonomous, but on larger and higher islands that support multiple phytogeographic zones this may not always be the case. The effect of merging several island communities into one assemblage would be to raise the observed species-genus ratio, increasing Type II error in one tailed tests. As I have already noted, the Antillean bat data are not handicapped by Type II error. 
Although depressed species-genus ratios may be considered concordant with Darwin's hypothesis of interspecific competition, Grant and Abbott (1980) have noted that many other forces or processes might be involved. A fauna with a long history of coexistence might contain a number of highly convergent taxa with similar niche requirements but generically distinct identities. Such taxa would have the potential for high levels of interspecific competition but would be characterized by a low species-genus ratio. It is possible that the smaller deviations between the observed and expected numbers of genera in the Greater Antilles, relative to the Lesser Antilles, may relate in part to this phenomena.

The adoption of Varona's (1974) conservative classification would reduce the endemic stenodermine taxa from four monotypic genera (Ariteus, Stenoderma, Phyllops and Ardops) to a single genus (Stenoderma) and correspondingly raise the species-genus ratios of simulated species assemblages. However, since the endemic stenodermines are distributed in a perfect checkerboard pattern (sensu Diamond, 1975), the species-genus ratios of the observed data sets would not be affected and the result would be to increase the dichotomy between the observed pattern and the null model.

The pattern of archipelago-wide depressed species-genus ratios exhibited by the Antillean bat fauna is counter to the generalized observations of Simberloff (1970), but is in accord with the specific case studies of the Galapagos Island finches, Geospiza sp. (Connor and Simberloff 1978 ; Simberloff 1984). Although there is little agreement as to the processes structuring the Galapagos avifauna, Harvey et al. (1983) have noted that on small islands with a narrow spectrum of resources competitive interaction should be enhanced and the species-genus ratios increasingly depressed. The demonstration in this study that the magnitude of the species-genus ratio shift in Antillean bats is indeed inversely correlated with island size provides some circumstantial support for Darwin's interspecific competition hypothesis. Taken together with evidence for a pattern of highly structured species co-occurrence in Antillean bat assemblages (McFarlane 1989), the argument that interspecific competition plays a significant role in the structuring of the Antillean bat fauna becomes increasingly persuasive.

\section{BIBLIOGRAPHY}

BakeR, R.J. and H.H. Genoways, 1978. - Zoogeography of Antillean bats. Spec. Publ. Nat. Acad. Sci. Phila., 13 : 53-97.

Baker, R.J., H.H. Genoways and J.C. Patton, 1978. - Bats of Guadeloupe. Occas. Pap. Mus. Tex. Tech. Univ., 50 : 1-16.

CONNOR, E.F. and D. SimberLOFF, 1978. - Species number and compositional similarity of the Galapagos flora and avifauna. Ecol. Monogr., 48 : 219-248.

DiAmOND, J.M., 1975. - Assembly of species communities, pp. 342-444, in : Ecology and Evolution of Communities (M.L. Cody and J.M. Diamond, eds.). Belknap Press, Cambridge. 545 pp.

DARWIN, C., 1878. - The origin of species. Sixth ed. Appleton and Company, New York, $386 \mathrm{pp}$.

Elton, C.S., 1946. - Competition and the structure of ecological communities. J. Anim. Ecol., 15 : 54-68. 
Grant, P.R., 1966. - Ecological compatibility of bird species on islands. Amer. Nat., $100: 451-462$.

Grant, P.R. and I. AbBott, 1980. - Interspecific competition, island biogeography and null hypotheses. Evolution, 34 : 332-341.

GRIFFITHS, T.A. and D. KLINGENER, 1988. - On the distribution of Greater Antillean bats. Biotropica, $20: 240-251$.

HaRvey, P.H., R.K. Colwell, J.W. Silvertown and R.M. May, 1983. - Null models in ecology. Ann. Rev. Ecol. Syst., 14 : 189-211.

Hill, J.E. and P.G.H. Evans, 1985. - A record of Eptesicus fuscus (Chiroptera : Vespertilionidae) from Dominica, West Indies. Mammalia, 49 : 133-136.

HOPF, F.A. and J.H. BROWN, 1986. - The bulls-eye method for testing randomness in ecological communities. Ecology, $67: 1139-1155$.

LACK, D., 1976. - Island biology, illustrated by the land birds of Jamaica. Univ. of California Press, Berkeley and Los Angeles, $445 \mathrm{pp}$.

LAZELL, J.D. and L. JARECKI, 1985. - Bats of Guana, British Virgin Islands. Am. Mus. Novit., 2819 : 1-7.

JONES, J.K., 1978. - A new bat of the genus Artibeus from the Lesser Antillean island of St. Vincent. Occas. Pap. Mus. Tex. Tech. Univ., $60: 1-6$.

KocK, D. and H. STEPHAN, 1986. - Une chauve-souris nouvelle pour la Martinique, Antilles françaises: Monophyllus plethedon luciae. Mammalia, $50: 268$.

MCFARLANE, D.A., 1989. - Patterns of species co-occurrence in the Antillean bat fauna. Mammalia, 53 : 59-66.

OtTEnwalder, J.A. and H.H. GenOwAys, 1982. - Systematic review of the bats of the Antillean bats of the Natalus micropus complex (Chiroptera : Natalidae). Ann. Carnegie Mus., 51 : 1-38.

Pierson, E.D., W.E. Rainey, R.M. Warner and C.C. White-Warner, 1986. - First record of Monophyllus from Montserrat, West Indies. Mammalia, $50: 269$.

SimberlofF, D., 1970. - Taxonomic diversity of island biotas. Evolution, 24 : 23-47.

SIMBERlofF, D., 1984. - Properties of co-existing bird species in two archipelagoes. Pp. 234-253, in : Ecological communities: conceptual issues and the evidence (D.R. Strong et al., eds.). Princeton Univ. Press, Princetown, New Jersey, 613 pp.

SOKAL, R.R. and F.J. ROHLF, 1981. - Biometry : The principles and practice of statistics in biological research. W.H. Freeman and Co., San Francisco, 859 pp.

Varona, L.S., 1974. - Catalogo de los Mammiferos Viventes y extinguidos de las Antillas. Acad. de Cien. de Cuba, Havana, 139 pp.

ZAR, J.H., 1984. - Biostatistical Analysis. 2nd ed. Prentice-Hall Inc., Englewood Cliffs; New Jersey, $718 \mathrm{pp}$. 
Appendix 1. - Presence-absence data for bats on 25 Antillean islands.

Cuba : Noctilio leporinus (Nol), Pteronotus parnelli (Ptp), Pteronotus fuliginosus (Ptf), Pteronotus macleayi (Ptm), Mormoops blainvilli (Mob), Macrotus waterhousi (Maw), Monophyllus redmani (Mnr), Artibeus jamaicensis (Arj), Brachyphylla nana (Brn), Erophylla sezekorni (Ers), Phyllonycteris poeyi (Php), Phllops falcatus ( $\mathrm{Phf})$, Natalus lepidus (Nal), Natalus micropus $(\mathrm{Nam})$, Eptesicus fuscus (Epf), Lasiurus pfeifferi (Laf), Lasiurus intermedius (Lai), Nycticeius humeralis (Nyh), Antrozous pallidus (Anp), Tadarida brasiliensis (Tab), Tadarida laticaudatus (Tal), Tadarida macrotis (Tam), Mormopterus minutus (Mrm), Eumops glaucinus (Eug), Eumops perotis (Eup), Molossus molossus (Mlm).

Hispaniola : Nol, Ptp, Ptf, Mob, Maw, Mnr, Arj, Phyllops haitiensis, Brn, Erophylla bombifrons (Erb), Php, Nam, Natalus major (Naa), Epf, Lasiurus minor (Lam), Tab, Tam, Mlm.

Jamaica : Tol, Ptp, Ptf, Ptm, Mob, Maw, Mar, Gls, Arj, Ariteus flavescens, Ers, Phyllonycteris aphylla, Nam, Naa, Eptesicus lynni, Lasiurus deglida, Tab, Tam, Eug, Eumops auripendulus, Mlm.

Puerto Rico : Nol, Ptp, Ptf, Mob, Mnr, Arj, Stenoderma rufum (Str), Bachyphylla cavernarum (Brc), Erb, Epf, Lam, Tab, Mlm.

Guadeloupe: Nol, Monophyllus plethedon (Mnp), Arj, Ardops nichollsi (Arn), Sturnira thomasi, Chiroderma improvisum (Chi), Brc, Natalus stramineus (Nas), Eptesicus guadeloupensis, Tab, Mlm.

Martinique : Nol, Pteronotus davyi (Ptd), Mnp, Arj, Adn, Sturnira lilium (Stl), Brc, Myotis martiniquensis (Mym), Tab, Mlm.

Dominica : Nol, Ptd, Mnp, Arj, Adn, Stl, Brc, Nas, Epf, Myotis dominicensis, Tab, Mlm.

St. Lucia : Nol, Mnp, Arj, Adn, Stl, Brc, Tab, Mlm.

Barbados: Nol, Mnp, Arj, Brc, Mym, Mlm.

St. Vincent : Nol, Mnp, Glossophaga longirostris (Gll), Arj, Artibeus lituratus (Arl), Adn, Stl, Brc, Mlm.

Antigua : Nol, Mnp, Arj, Brc, Nas, Tab, Mlm.

Grenada : Nol, Ptd, Peropteryx macrotis, Micronycteris megalotis, Gll, Anoura geoffroyi, Arj, Arl, Artibeus cinereus, Carollia perspicallata, Myotis nigricans, Mlm.

St. Croix : Nol, Arj, Brc, Mlm.

Grand Cayman: Maw, Arj, Brn, Ers, Epf, Tab, Mlm, Phf.

St. Kitts : Nol, Arj, Tab, Mlm.

Barbuda : Nol, Mnp, Arj, Brc, Tab, Mlm.

Montserrat: Nol, Mnp, Arj, Adn, Chi, Brc, Nas, Tab, Mlm.

Anguilla : Mnp, Arj, Brc, Nas, Mlm.

St. Martin : Nol, Arj, Brc, Tab, Mlm.

St. Eustatius : Arj, Adn, Brc, Tab, Mlm.

Saba : Arj, Brc, Nas.

St. John : Nol, Arj, Str, Brc, Tab, Mlm.

St. Thomas : Nol, Arj, Str, Brc, Mlm.

Tortola : Nol, Arj, Mlm.

Guana : Arj, Brc, Mlm.

Sources : Baker and Genoways (1978) ; Baker, Genoways and Patton (1978) ; Griffiths and Klingener (1988) ; Hill and Evans (1985) ; Jones (1978) ; Kock and Stephan (1986); Lazell and Jarecki (1985); Ottenwalder and Genoways (1982); Pierson et al. (1986). 